\section{CONSISTENCY OF FLY ASH QUALITY FOR MAKING HIGH VOLUME FLY ASH CONCRETE}

Antoni*, Alvin Krisnanta Widianto, Jerry Lakshmana Wiranegara, Djwantoro Hardjito

Civil Engineering Department, Petra Christian University, Surabaya 60236, Indonesia
Article history

Received

10 March 2017

Received in revised form

18 July 2017

Accepted

6 September 2017

*Corresponding author antoni@petra.ac.id
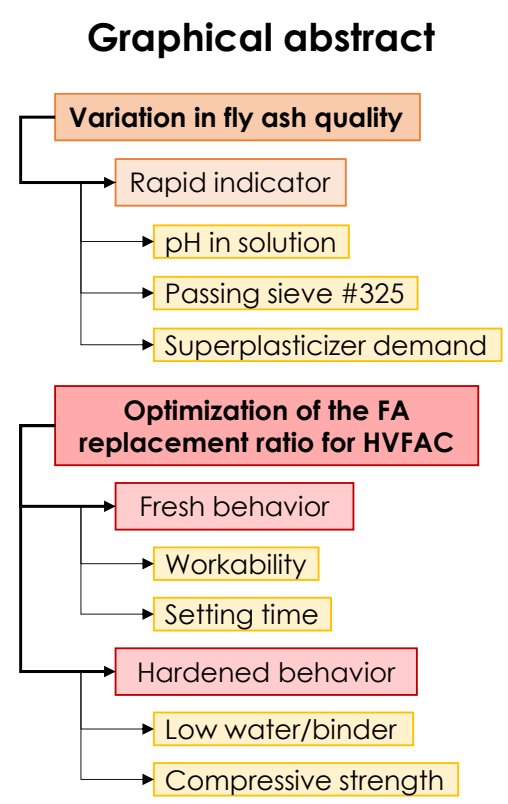

\begin{abstract}
Fly ash is a by-product of coal burning and is widely used as a substitute for cement material. The advantages of using fly ash in concrete include the improvement of workability and reduction of bleeding and segregation. The problem often encountered when using fly ash is the uncertainty of the fly ash quality. The quality is influenced by the coal origin, burning technique, mineral content, and capturing method. In this study, the consistency of fly ash from one power plant source was investigated for making a high-volume fly ash (HVFA) mortar. Variations in fly ash can be detected by applying rapid indicators as suggested in this paper; i.e., the pH of the fly ash in aqueous solution, the percentage of fly ash particles passing sieve \#325 and the superplasticizer demand for the targeted slump flow. The fly ash replacement ratio was varied from 10-60\% of cement, by mass. The results showed a large variation in the chemical content of the fly ash as shown by variation in $\mathrm{pH}$, whereas only slight variation in the physical properties of the fly ash, i.e. particle size and shape. Superplasticizer demand for the same flow diameter was reduced with the increase of fly ash content, whereas the optimum fly ash replacement ratio for maximum strength varied among fly ash from different sampling periods. The compressive strength could reach that of control specimens at a replacement ratio of $20-30 \%$, and mortar compressive strength of $42 \mathrm{MPa}$ was still achievable at a replacement ratio of $50 \%$.
\end{abstract}

Keywords: Fly ash, pH, HVFA, LOI, setting time, compressive strength

(C) 2017 Penerbit UTM Press. All rights reserved

\subsection{INTRODUCTION}

The utilization of fly ash as an additive to concrete mixtures has gained popularity in past decades. The addition of fly ash is known to have beneficial effects such as increased workability, reduction of water requirement, reduction of bleeding and segregation, reduction of alkali silica reaction, and other benefits. Many papers have been published on the properties of fly ash and its effects on concrete mixtures [1-5]. The use of fly ash in concrete mixtures should be encouraged as the availability of fly ash keeps increasing along with the new coal-burning power plants being constructed to meet rising electrical energy demand. Guides and handbooks to determine the suitability and use of fly ash in concrete have been published by several researchers and organizations [614] that show fly ash can be used in large volume for concrete casting.

The characteristics of fly ash have been studied extensively by many authors [15-22]. Simple methods to characterize the variation of fly ash properties also have been presented by the authors [23] that can detect changes in fly ash properties more quickly and inexpensively than other methods. Research on improving fly ash properties also has been done to increase utilization of lower-quality fly ash [24, 25]. 
The quality of fly ash, a by-product of coal-burning, is not a concern for the power plant, which is only interested in obtaining the highest energy output. Given the different compositions of coal, fly ash quality can deviate significantly in both its physical and chemical properties, which could lead to problems when mixed with concrete.

Variations of fly ash characteristics include chemical properties, calcium content, particle size and shape, reactivity, and the loss on ignition (LOI) of the sample. These different fly ash characteristics results in differences to fresh and hardened concrete properties [26-30].

This study investigated the characteristics of fly ash samples at one power plant. The fly ash source used was well-known in the concrete industry to yield a good-quality fly ash. Changes to fresh and hardened mortar properties in relation to fly ash properties need to be understood, particularly when replacing cement with larger volumes of fly ash. Rapid indicators, i.e. $\mathrm{pH}$, particle size and superplasticizer demand, were investigated to determine its correlation to the fresh and hardened properties of the mortar.

\subsection{METHODOLOGY}

\subsection{Materials and Mortar Mixture Preparation}

Ten fly ash samples were collected periodically, once in every two weeks, from an electric power plant in Paiton, East Java, Indonesia, from July to October 2015. Pozzolan Portland Cement (PPC) from Semen Gresik was obtained in sealed bags to avoid variation of the cement material. Good quality sand was obtained from Lumajang quarry, East Java, and conditioned to conform to a gradation of ASTM C778 [31]. The graded sand was prepared to ensure that the variation of workability would not be caused by the variation of the sand gradation. Polycarboxylatebased Viscocrete 1003 from SIKA was used as the superplasticizer (SP).

The mixture proportion for all mortar mixtures was as follows: the water to binder (fly ash and cement) ratio was fixed at 0.30; sand to binder ratio was 2.0 (both by mass); and the superplasticizer dosage was aimed to achieve a diameter of $14 \pm 2 \mathrm{~cm}$, by flow table test, and designated as the "superplasticizer demand."

The dosage of fly ash as cement replacement were set at $10 \%, 20 \%, 30 \%, 40 \%, 50 \%$, and $60 \%$, of the total binder, by mass. A control specimen of only cement and sand was also prepared. Lowering water to binder ratio was a necessity to increase the compressive strength and the addition of fly ash enhanced the mixture cohesion and its workability.

The mortar mixture was mixed using a hand drill to obtain a uniform mixture and cast as $5 \mathrm{~cm} \times 5 \mathrm{~cm} \times 5$ $\mathrm{cm}$ specimens. The specimens were demolded one day after mixing and cured under water until one day prior to compressive testing.

\subsection{Testing}

The fly ash was passed through sieve size \#325 (44 $\mu \mathrm{m}$ ) and the $\mathrm{pH}$ of the particulate fly ash was measured in aqueous solution. The solution was prepared by putting $20 \mathrm{~g}$ fly ash into $80 \mathrm{ml}$ distilled water, according to ASTM D5239 [32]. The $\mathrm{pH}$ test provided rapid determination of the fly ash quality. Four fly ash samples were also analyzed using X-ray fluorescence (XRF) to determine their chemical compounds, and $\mathrm{LOI}$ tests to measure their the un-burnt carbon content.

Workability of the fly ash and cement mixture and the superplasticizer (SP) demand were determined using a flow table test [33]. The addition of the SP into the mixture was conducted to achieve a target flow diameter of $14 \pm 2 \mathrm{~cm}$. The SP dosage was limited to $2 \%$ of cement mass to avoid excessive retardation and bleeding. Higher dosage could also reduce the final compressive strength.

The setting time was determined by measuring the temperature rise of the paste mixture according to ASTM C1679 [34]. The compressive strength was measured at mortar age of $3,7,14,28$, and 56 days, respectively. Three cube specimens were tested for each compressive strength test. The results given in various Figures and Tables are the mean of these values.

\subsection{RESULTS AND DISCUSSIONS}

\subsection{Fly Ash Variation}

Ten fly ash samples, designated as FA-I to FA-X, were obtained from an electric power plant source within four months period. The $\mathrm{pH}$ and percentage of material, in mass, passing sieve \#325 are shown in Table 1. All fly ash samples were shown to have a fine particle size exceeding the ASTM C618 requirement of $66 \%$ passing the sieve [35]. The $\mathrm{pH}$ values ranged from 10.4 to 11.8 , indicating a potentially large variation in chemical composition.

Table $1 \mathrm{pH}$ and Particle Size of Fly Ash Samples

\begin{tabular}{lccccccccccc}
\hline \multirow{2}{*}{ Fly ash } & $\begin{array}{c}\text { FA- } \\
\text { I }\end{array}$ & II & III & IV & V & VI & VII & VIII & IX & X \\
\hline pH & 10.9 & 11.1 & 10.4 & 11.8 & 10.6 & 10.8 & 10.6 & 11.7 & 11.4 & 11.2 \\
\hline $\begin{array}{l}\text { Passing sieve } \\
\# 325(\%)\end{array}$ & 84 & 88 & 76 & 88 & 80 & 84 & 84 & 88 & 92 & 84 \\
\hline
\end{tabular}

Four fly ash samples were sent for XRF analysis to measure their chemical compositions. The XRF results are shown in Table 2. It was found that the $\mathrm{pH}$ had good correlation with the $\mathrm{CaO}$ and $\mathrm{MgO}$ content. The $\mathrm{CaO}$ content was in the range of medium to high; hence, the fly ash can be categorized as class $C$ fly ash. The chemical composition had a broad range of percentages, which affects the predictability of the properties of the fresh and hardened concrete. 
The loss on ignition (LOI) values of the fly ash are also shown in Table 2. It was found that the fly ash taken from this source had a good and constant low LOI of less than $1 \%$, indicating an excellent burning process in the power plant. Thus, there was no large variation in physical properties, whereas the chemical properties of fly ash from the same plant varied between collections. This chemical variation cannot be avoided because of the different coal source used in the combustion process, as the power plant sourced its coal from three different quarries.

Table 2 Chemical Compositions of Selected Fly Ash Samples as Measured by XRF

\begin{tabular}{lrrrr}
\hline \multirow{2}{*}{ Compound } & \multicolumn{4}{l}{ Chemical Composition (\% mass) } \\
\cline { 2 - 5 } & FA-II & FA-III & FA-IV & FA-V \\
\hline $\mathrm{SiO}_{2}$ & 43.74 & 43.36 & 32.47 & 42.26 \\
\hline $\mathrm{Al}_{2} \mathrm{O}_{3}$ & 22.03 & 29.74 & 14.92 & 24.43 \\
\hline $\mathrm{Fe}_{2} \mathrm{O}_{3}$ & 14.68 & 7.33 & 16.50 & 12.91 \\
\hline $\mathrm{CaO}$ & 9.40 & 13.30 & 20.42 & 11.19 \\
\hline $\mathrm{K}{ }_{2} \mathrm{O}$ & 1.55 & 0.42 & 1.32 & 0.80 \\
\hline $\mathrm{MgO}$ & 4.33 & 1.80 & 7.95 & 3.69 \\
\hline $\mathrm{SO}_{3}$ & 0.53 & 0.40 & 1.88 & 0.91 \\
\hline $\mathrm{Mn}_{2} \mathrm{O}_{3}$ & 0.15 & 0.14 & 0.18 & 0.24 \\
\hline $\mathrm{TiO}_{2}$ & 1.28 & 1.00 & 0.71 & 1.01 \\
\hline $\mathrm{Cr}_{2} \mathrm{O}_{3}$ & 0.14 & 0.01 & 0.14 & 0.01 \\
\hline $\mathrm{Na}_{2} \mathrm{O}$ & 1.56 & 1.88 & 2.92 & 1.85 \\
\hline $\mathrm{LOI}$ & 0.80 & 0.60 & 0.43 & 0.44 \\
\hline
\end{tabular}

\subsection{Fresh Mortar Behavior}

The superplasticizer demand for a target flow of $14 \pm 2$ $\mathrm{cm}$ by flow table test and the resulting flow diameters are shown in Figures 1 and 2, respectively. The control specimen required up to $2 \%$ of SP to achieve a flow diameter of $11 \mathrm{~cm}$. The increase of the fly ash content reduced SP demand and increased the flow diameter. This is the norm with fly ash usage due to the increase of round particles in the mixture, which increases the bearing ball effect. The presence of fly ash with its fine particle size also increases the availability of free water content that is normally trapped between cement particles.

The SP demand for mortar with FA-III, FA-IV and FA$\checkmark$ at $30 \%$ and $40 \%$ replacement ratio was slightly higher than those with other fly ash; however, there was no detrimental effect on the flow properties. The SP demand needs to be determined for the concrete mixture when obtaining a new batch of fly ash as it could affect the concrete's workability. The difference in SP dosage of about $0.25 \%$ could cause the mixture to be stiff or slightly bleeding, depending on the fly ash variation.

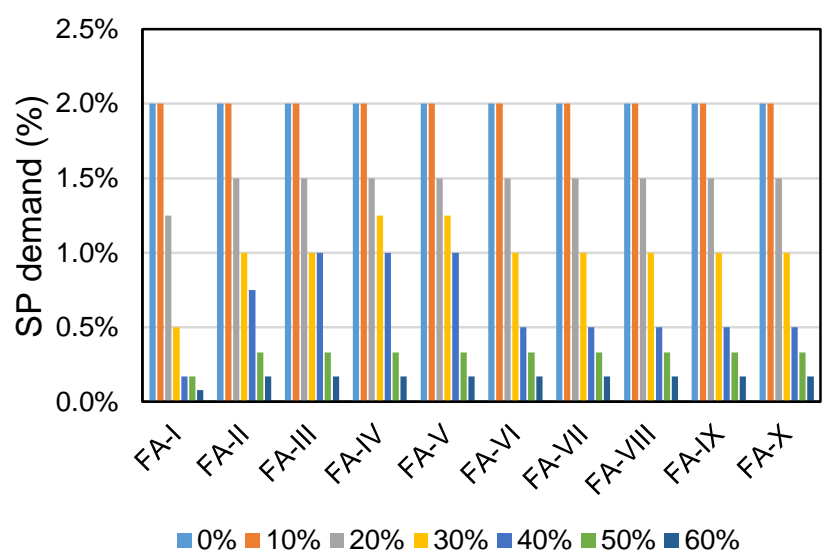

Figure 1 Superplasticizer demand for targeted flow

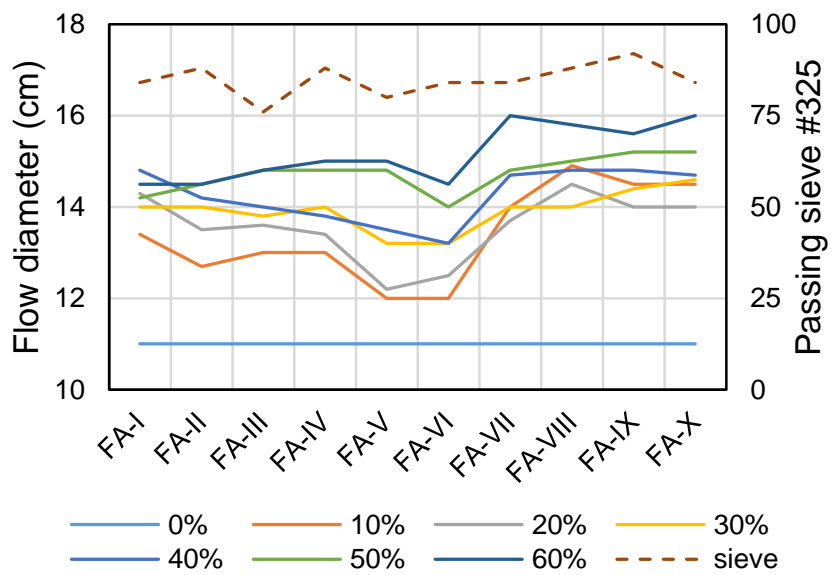

Figure 2 Flow of the fly ash mortar and percentage passing sieve \#325

The increase of the fly ash replacement ratio increased the setting time of the mixture. The initial setting times of the mixture with different fly ash samples and replacement ratios are shown in Figure 3. The initial setting time was increased with the increase of fly ash content at various rate depending on the different fly ash samples. The increase of setting time could be beneficial when casting concrete in situ, as it would have a longer handling time. However, the opposite effect occurs when large volumes of fly ash are used in the precast industry, as the increased setting time would prolong the demolding cycle. A higher replacement ratio increases the setting time at higher rate as shown by paste with FA-IV and FA-IX. 


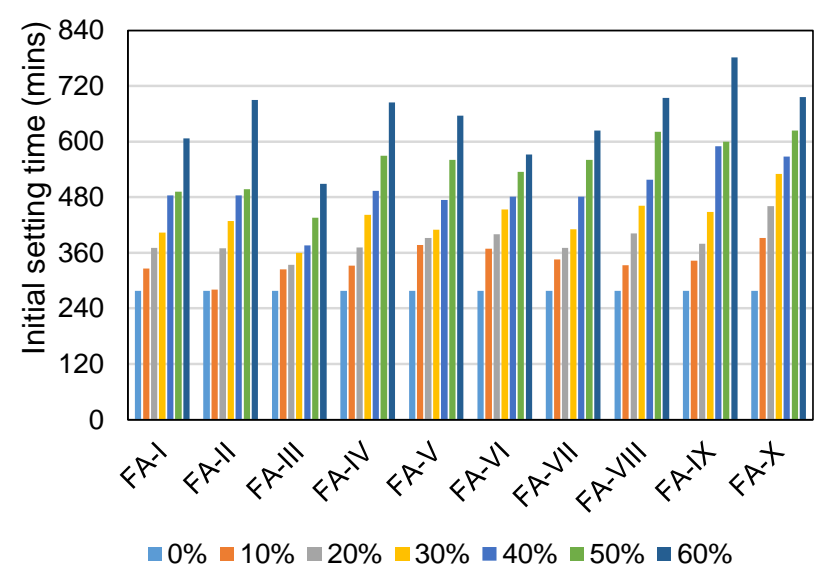

Figure $\mathbf{3}$ Initial setting time of the paste

\subsection{Strength Development}

The compressive strength values of the mortar specimens for all mixtures are shown in Figures 4-13. The control specimens had compressive strength of 45.8 MPa at 3 days and developed up to 67.4 MPa at 56 days. As expected, higher fly ash replacement ratios reduced the compressive strength, compared with the control specimen. The highest compressive strength of $73.3 \mathrm{MPa}$ at 56 days was attained from mortar with FA-VIII at $30 \%$ replacement ratio, which was higher than the control specimen. The lowest compressive strength of $37 \mathrm{MPa}$ at 56 days was recorded for mortar with $\mathrm{FA}-\mathrm{VI}$ at $60 \%$ replacement ratio.

The increase of compressive strength with age was found to be not uniform for mortar with different fly ash samples. An increase in compressive strength with the fly ash replacement-normally at a later age of mortar from 28 days to 56 days-was found for mortar with some fly ash samples, but not all. For instance, mortar samples with FA-I, FA-III, FA-IV, FA-V, and FA-IX showed strength increments at a later age, indicating the pozzolanic reaction occurs at this stage. However, those with FA-II, FA-VI, FA-VII, FA-VIII, and FA-X did not show significant increase of strength at a later age, which could be a sign of a low pozzolanic reaction rate. Mortar utilizing FA-VI and FA-VIII showed almost no increase in the compressive strength from 28 days to 56 days.

The different behavior of strength development could be due to the presence of calcium hydroxide in the gel solution. The cement used in this case was of pozzolanic Portland cement (PPC) type, meaning that extra calcium hydroxide could be consumed by the cement material itself. Therefore, fly ash with higher $\mathrm{CaO}$ content could contribute to later-age strength development. The other possibility is that fly ash with higher $\mathrm{CaO}$ content could have earlier pozzolanic reaction in the mixture, so that the most of the compressive strength is achieved earlier during the first 28 days, as could well be the case for FA-VIII mixture.

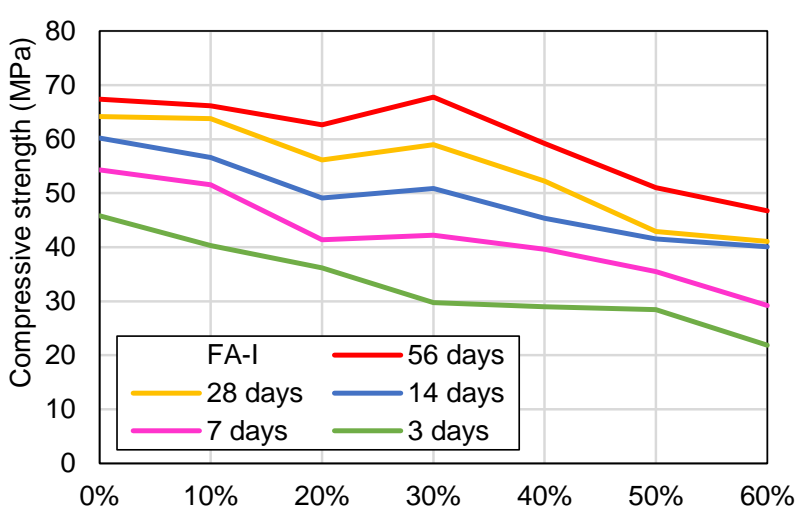

Fly ash replacement (\%)

Figure 4 Strength development of mortar with FA-I

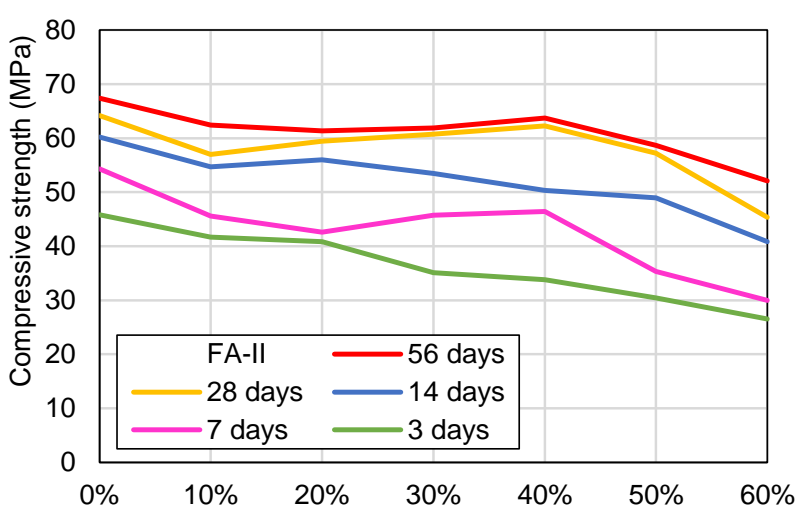

Fly ash replacement (\%)

Figure 5 Strength development of mortar with FA-II

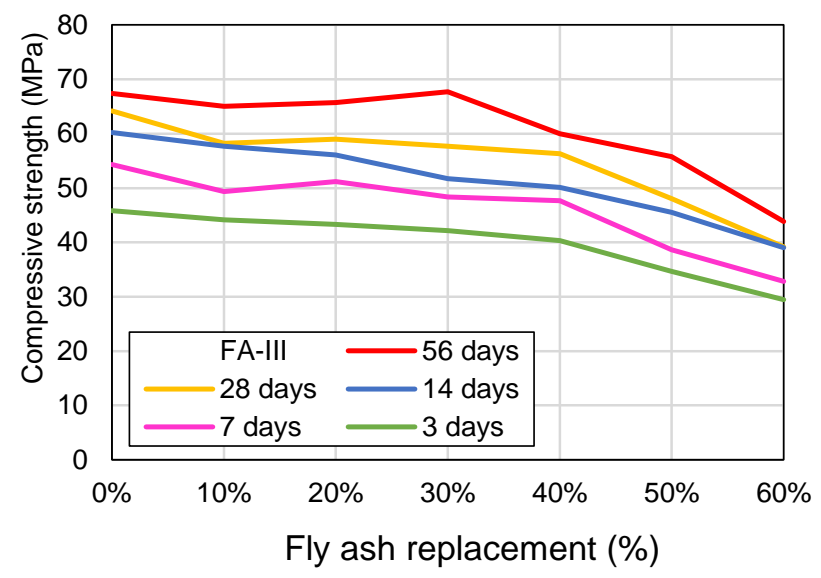

Figure 6 Strength development of mortar with FA-III

At the $10 \%$ fly ash replacement ratio, there was a slight drop of compressive strength and the workability of the mixture compared to those with higher fly ash replacement ratios, as shown in Figures 9 and 10, for mortar with FA-VI and FA-VII. This could be due to the difficulties encountered in the mixing process with lower water to binder ratio. The SP limit of $2 \%$ also 
limited the mixture's workability and the ball bearing effect of the fly ash was not effective enough in the mixture with the lower cement replacement ratio. Thus, it is suggested that the fly ash replacement ratio should be higher than $10 \%$ to benefit the effect of a more workable and compact mix.

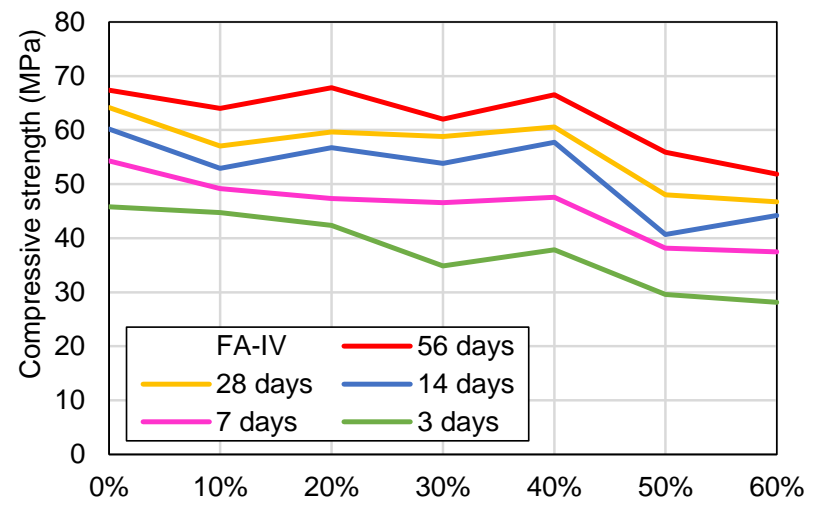

Fly ash replacement (\%)

Figure 7 Strength development of mortar with FA-IV

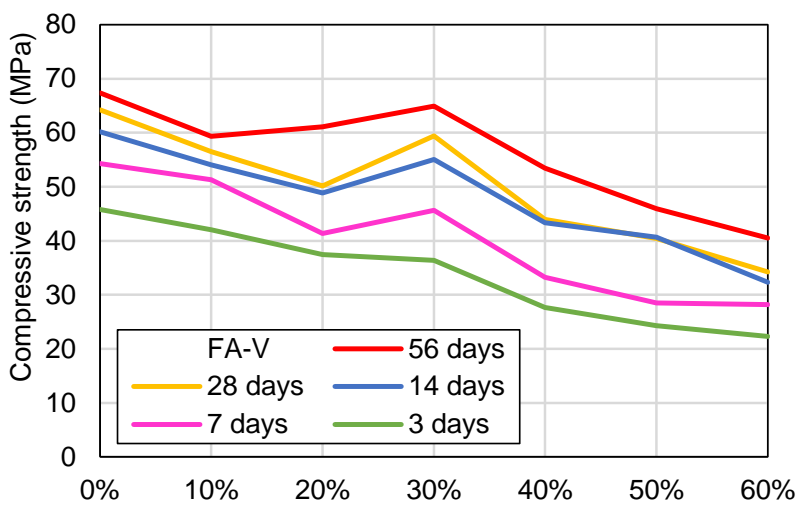

Fly ash replacement (\%)

Figure 8 Strength development of mortar with FA-V

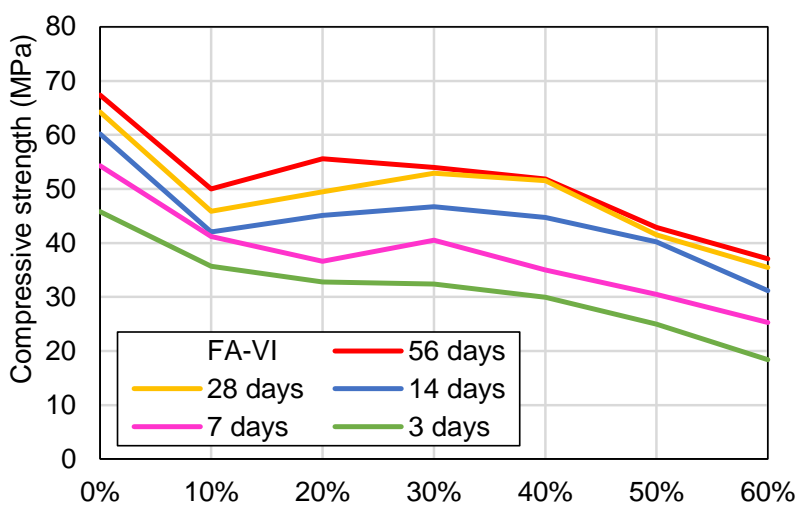

Fly ash replacement (\%)

Figure 9 Strength development of mortar with FA-VI

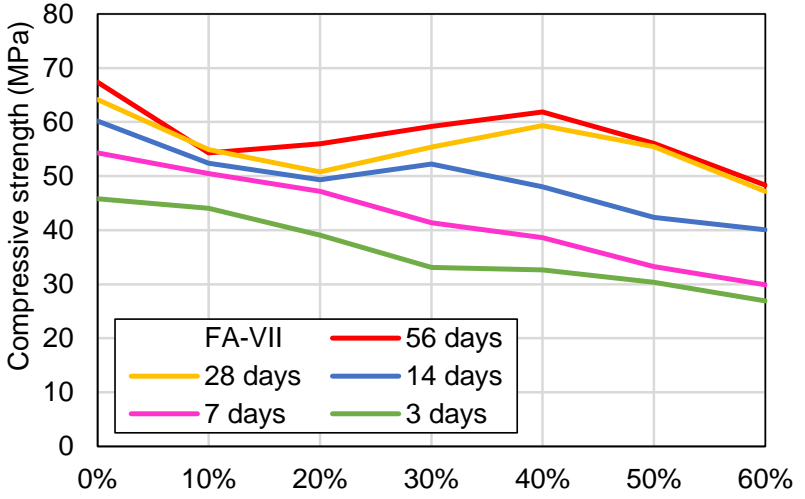

Fly ash replacement (\%)

Figure 10 Strength development of mortar with FA-VII

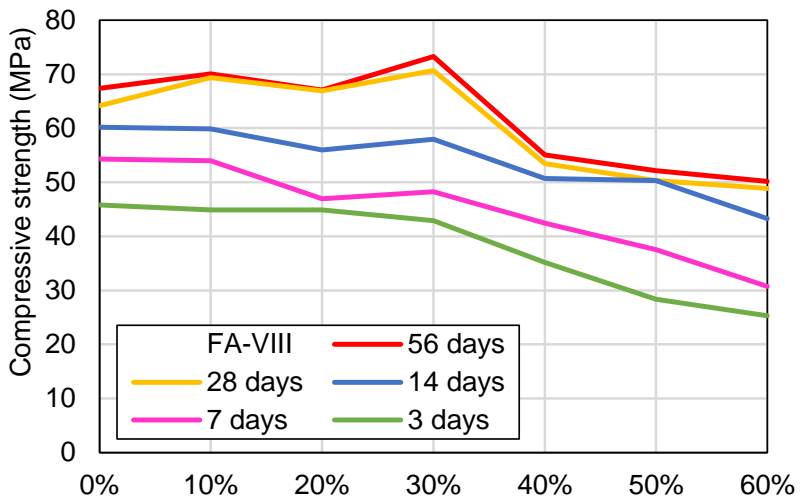

Fly ash replacement (\%)

Figure 11 Strength development of mortar with FA-VIII

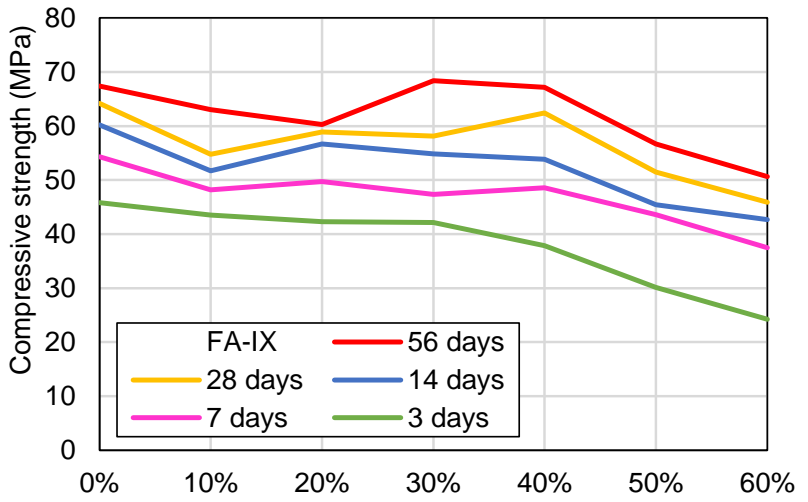

Fly ash replacement (\%)

Figure 12 Strength development of mortar with FA-IX 


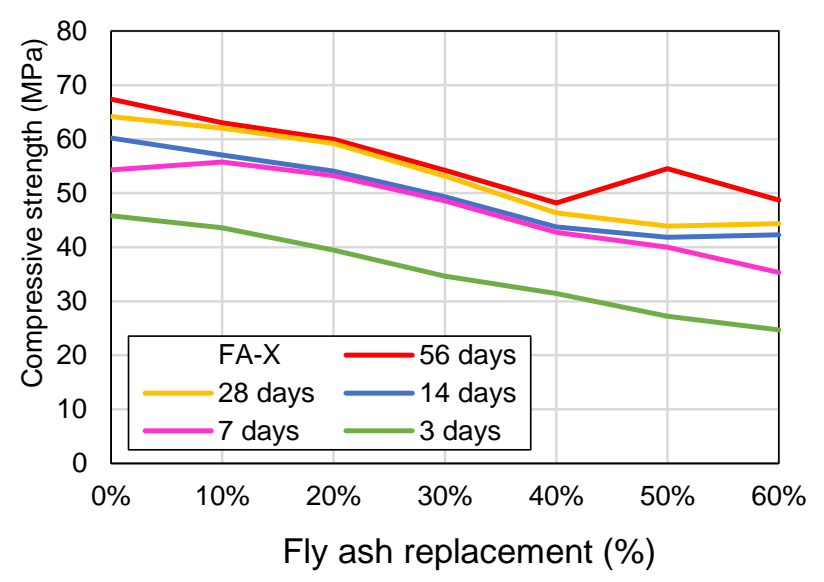

Figure 13 Strength development of mortar with FA-X

\subsection{Fly Ash Variations and Resulting Properties}

Peak hydration temperatures of the specimens were measured during the initial setting time evaluation. The correlation of peak temperatures and 3-day compressive strength of mortar specimens with different fly ash replacement ratios are shown in Figure 14. The peak temperatures vary with the fly ash used at the same replacement ratio, where higher peak temperature may indicate higher fly ash reactivity. Higher early age compressive strengths are obtained by paste specimens with higher peak temperatures.

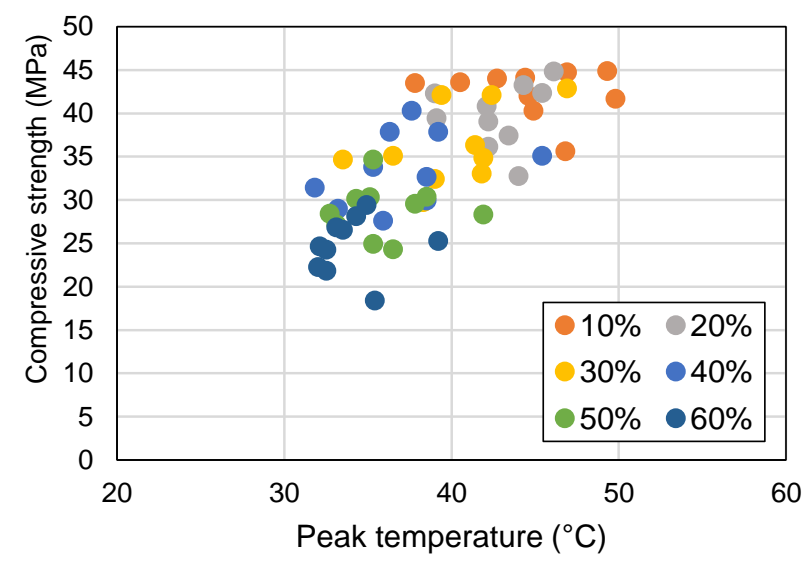

Figure 14 Relationship of peak temperature and 3-day compressive strength

The compressive strength values for the mortar specimens at 56 days are shown in Figure 15. This shows that all mortar specimens made from various mixes could have compressive strengths higher than 30 MPa; however, the maximum strength was not the same for comparable class $C$ fly ash replacement ratios. Different fly ash sampling times had a significant effect on the strength development and the peak compressive strength of mortar specimens, when other variables were held constant.

Mortar specimens produced with FA-V and FA-VI generally have lower strength compared with those with other fly ash samples. The effect was correlated with the slump flow (Figure 2), as fresh mortar with these two fly ash samples both had lower workability. Mortar produced with FA-VIII had the highest compressive strength compared with those with other fly ash samples, and the strength development was mostly taken place before 28 days (Figure 11).

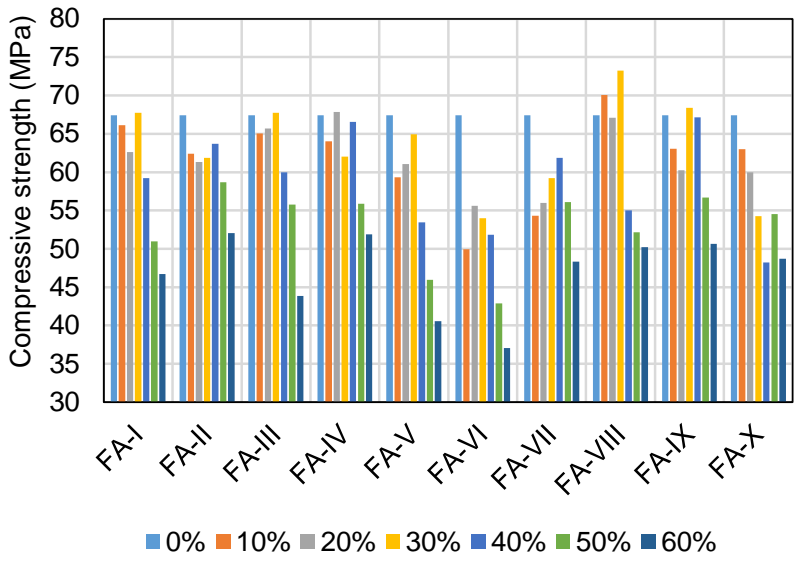

Figure 15 Overall compressive strength of mortar at 56 days

The correlations between initial setting time with $\mathrm{pH}$ of the fly ash are shown in Figure 16. The use of fly ash with higher $\mathrm{pH}$ had a retarding effect on the mortar mixture. This could be due to interaction of alkali content with the cement paste. Further study is needed to clarify the actual mechanism as higher fly ash replacement ratio and $\mathrm{pH}$ showed a longer initial setting time.

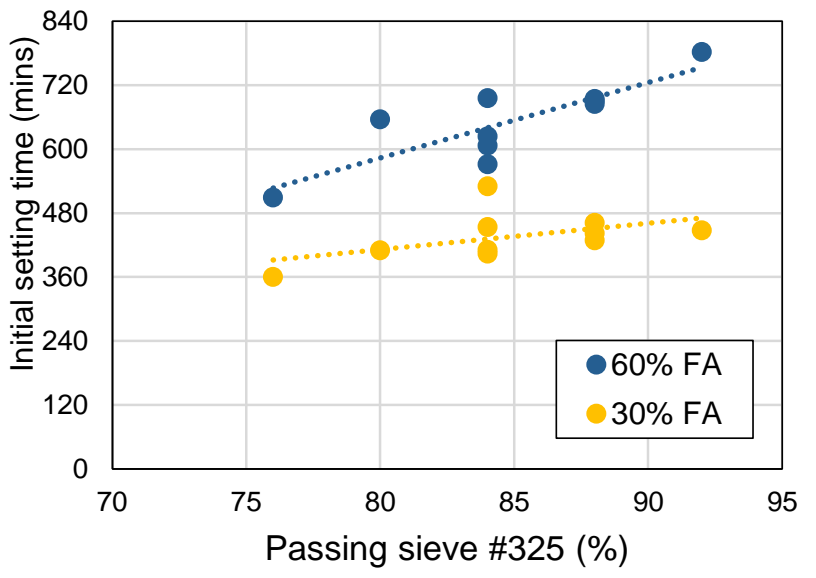

Figure 16 Relationship of initial setting time and $\mathrm{pH}$

The correlation of mortar compressive strengths at 56 days for fly ash replacement ratios of $30 \%$ and $60 \%$ and $\mathrm{pH}$ are graphed in Figure 17. The correlation of mortar compressive strengths at these ratios and fly ash particle size are graphed in Figure 18. Higher mortar compressive strength was obtained when using fly ash with higher $\mathrm{pH}$, which drives the additional hydration of the available $\mathrm{CaO}$. The increase of 
strength was more pronounced at higher replacement ratios. Finer fly ash particles also resulted in a better reaction in the mixture. The compressive strength of mortar at $60 \%$ fly ash replacement ratio had a positive correlation with finer particle size of fly ash.

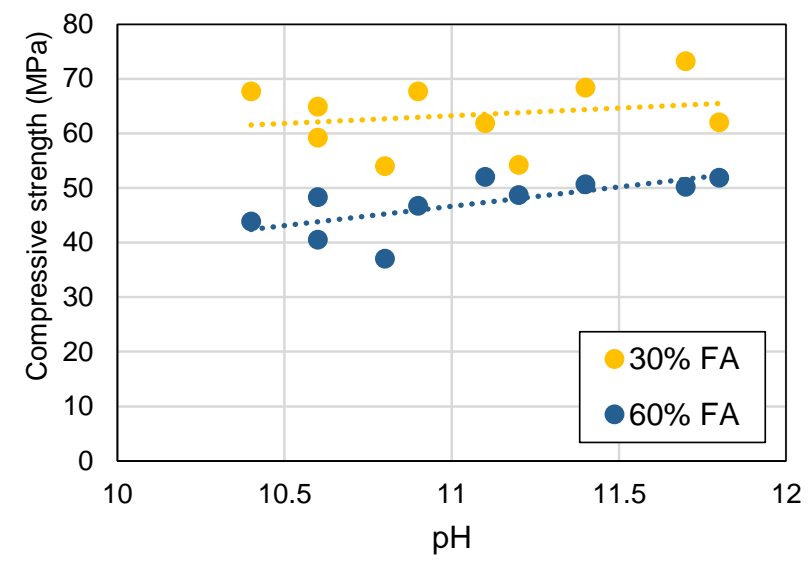

Figure 17 Relationship of compressive strength at 56 days and $\mathrm{pH}$

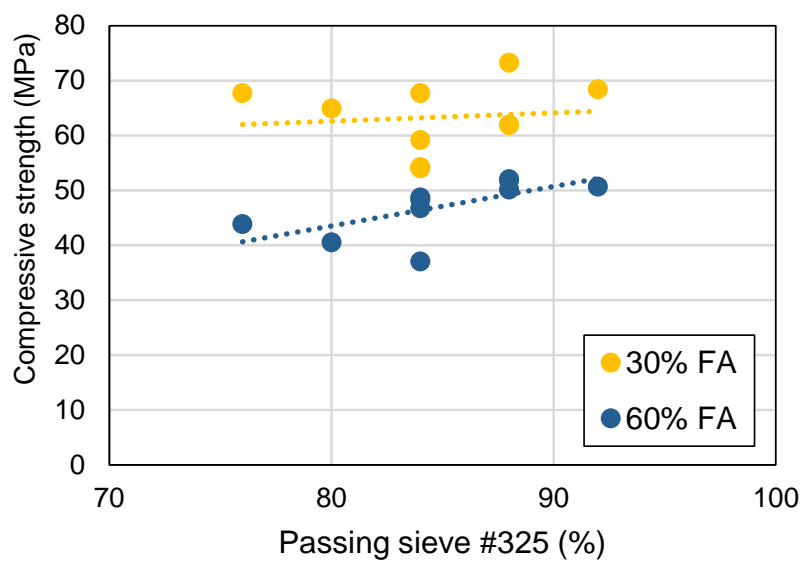

Figure 18 Relationship of compressive strength at 56 days and the percentage of passing sieve \#325

From the experimental data, it can be shown that the rapid indicators, i.e. the $\mathrm{pH}$ value and the percentage of fly ash particles passing sieve \#325, can determine critical predictive properties of fly ash, while the SP demand could give indication on the properties of the fly ash and determining the workability of the mixture. However, variations in fly ash quality are not limited to particle size and $\mathrm{pH}$ only, as other factors, such as LOI and particle shape also vary, depending on the coal-burning conditions. In particular, special care is needed when using fly ash after a power plant maintenance cycle, as the fly ash could have high LOI when the burning process is restarted.

\subsection{CONCLUSIONS}

The consistency of fly ash quality was investigated in this research and the following conclusions can be drawn:

There are changes of fly ash quality between shipments, especially in the chemical properties. It depends on the properties of coal that cannot be kept constant. Variation in fly ash quality affects the fresh and hardened properties of mortar or concrete.

Higher workability and longer setting time was found at higher fly ash replacement ratios. However, due to content variation, the optimum ratio needs to be determined for each shipment.

The optimum range of fly ash replacement ratio was found to be around $20-40 \%$. Some mortar specimens incorporating fly ash could have higher compressive strength than those of the control specimens without any fly ash, at replacement ratios of $30 \%$ and $40 \%$, and mortar compressive strength of $42 \mathrm{MPa}$ was still achievable with replacement ratio of $50 \%$.

The rapid indicator method implemented in this study (i.e., using pH, passing sieve \#325 and superplasticizer demand) can be used to assess the quality of fly ash and to estimate the resulting properties when high volumes of fly ash is mixed in concrete.

\section{Acknowledgements}

The authors gratefully acknowledge The Ministry of Research, Technology and Higher Education, Indonesia, who provided the research grant under the Fundamental Research scheme.

\section{References}

[1] Ahmaruzzaman, M. 2010. A Review on the Utilization of Fly Ash. Progress in Energy and Combustion Science. 36: 327363.

[2] Blissett, R. S., and Rowson, N. A. 2012. A Review of the MultiComponent Utilisation of Coal Fly Ash. Fuel. 97: 1-23.

[3] Deo, S. V. 2014. A Review of High Volume Low Lime Fly Ash Concrete. International Conference on Biological, Civil and Environmental Engineering BCEE-2014. Dubai UAE.

[4] Yao, Z. T., Ji, X. S., Sarker, P. K., Tang, J. H., Ge, L. Q., Xia, M. S., and Xi, Y. Q. 2015. A Comprehensive Review on the Applications of Coal Fly Ash. Earth-Science Reviews. 141: 105-121.

[5] Cao, D.-z., Selic, E., and Herbell, J.-D. 2008. Utilization of Fly Ash from Coal-fired Power Plants in China. Journal of Zhejiang University Science. 9: 681-687.

[6] Australia, A. D. A. O. 2009. Guide to the Use of Fly Ash in Concrete in Australia. Fly Ash Reference Data Sheet No. 1. Ash Development Association of Australia.

[7] Australia, A. D. A. O. 2009. Australian Experience with Fly Ash in Concrete: Applications and Opportunities. Fly Ash Technical Note No. 8. Ash Development Association of Australia.

[8] Bentz, D. P., Ferraris, C. F., and Snyder, K. A. 2013. Best Practices Guide for High-Volume Fly Ash Concretes. NIST Technical Note 1812. 
[9] Obla, K. H. 2008. Specifying Fly Ash for Use in Concrete. Concrete in Focus. 60-66.

[10] Rao, C., Stehly, R. D., and Ardani, A. 2011. Handbook for Proportioning Fly Ash as Cementitious Material in Airfield Pavement Concrete Mixtures, Foundation. I. P. R., Ed. IL, USA. 74.

[11] Rashad, A. M. 2015. A Brief on High-volume Class F Fly Ash as Cement Replacement-A Guide for Civil Engineer. International Journal of Sustainable Built Environment. 4: 278306.

[12] Thomas, M. 2007. Optimizing the Use of Fly Ash in Concrete. Portland Cement Association Skokie, IL, USA. 5420.

[13] Wesche, K. 2004. Fly Ash In Concrete: Properties and Performance. CRC Press. 7.

[14] Rivera, F., Martínez, P., Castro, J., and López, M. 2015. Massive Volume Fly-ash Concrete: A More Sustainable Material with Fly Ash Replacing Cement and Aggregates. Cement and Concrete Composites. 63: 104-112.

[15] Blanco, F., Garcia, M. P., and Ayala, J. 2005. Variation in Fly Ash Properties with Milling Aand Acid Leaching. Fuel. 84: 8996.

[16] Fernández-Jiménez, A., and Palomo, A. 2003. Characterisation of Fly Ashes. Potential Reactivity As Alkaline Cements. Fuel. 82: 2259-2265.

[17] Hemalatha, T., Mapa, M., George, N., and Sasmal, S. 2016. Physico-chemical and Mechanical Characterization of High Volume Fly Ash Incorporated and Engineered Cement System Towards Developing Greener Cement. Journal of Cleaner Production. 125: 268-281.

[18] Jones, M., McCarthy, A., and Booth, A. 2006. Characteristics of the Ultrafine Component of Fly Ash. Fuel. 85: 2250-2259.

[19] Romagnoli, M., Sassatelli, P., Lassinantti Gualtieri, M., and Tari, G. 2014. Rheological Characterization of Fly Ash-based Suspensions. Construction and Building Materials. 65: 526534.

[20] Siddique, R. 2004. Performance Characteristics of HighVolume Class Fly Ash Concrete. Cement and Concrete Research. 34: 487-493.

[21] Supit, S. W. M., Shaikh, F. U. A., and Sarker, P. K. 2014. Effect of Ultrafine Fly Ash on Mechanical Properties of High Volume Fly Ash Mortar. Construction and Building Materials. 51: 278-286.

[22] Wang, X.-Y. 2014. Effect of Fly Ash on Properties Evolution of Cement Based Materials. Construction and Building Materials. 69: 32-40.
[23] Antoni, Gunawan, R., and Hardjito, D. 2015. Rapid Indicators in Detecting Variation of Fly Ash for Making HVFA Concrete. Applied Mechanics and Materials. 815: 153-157.

[24] Antoni, Satrya, V. and Hardjito, D. 2015. Simple Mechanical Beneficiation Method of Coarse Fly Ash with High LOI for Making HVFA Mortar. Civil Engineering Dimension. 17.

[25] Blanco, F., Garcia, M. P., Ayala, J., Mayoral, G., and Garcia, M. A. 2006. The Effect of Mechanically and Chemically Activated Fly Ashes on Mortar Properties. Fuel. 85: 20182026.

[26] Shaikh, F. U. A., and Supit, S. W. M. 2015. Compressive Strength and Durability Properties of High Volume Fly Ash HVFA Concretes Containing Ultrafine Fly Ash UFFA. Construction and Building Materials. 82: 192-205.

[27] Hela, R., Tazky, M., \& Bodnarova, L. 2016. Possibilities of Determination of Optimal Dosage of Power Plant Fly Ash for Concrete. Jurnal Teknologi. 78(5-3).

[28] Yazici, \$., and Arel, H. \$. 2012. Effects of Fly Ash Fineness on the Mechanical Properties of Concrete. Sadhana. 37: 389403.

[29] Nawaz, A., Julnipitawong, P., Krammart, P., and Tangtermsirikul, S. 2016. Effect and Limitation of Free Lime Content in Cement-fly Ash Mixtures, Construction and Building Materials. 102: 515-530.

[30] Tkaczewska, E. 2014. Effect of the Superplasticizer Type on the Properties of the Fly Ash Blended Cement. Construction and Building Materials. 70: 388-393.

[31] ASTM. 2005. C778, Standard Specification For Standard Sand. ASTM International.

[32] ASTM. 2003. D5239, Standard Practice for Characterizing Fly Ash for Use in Soil Stabilization. American Society for Testing and Materials. ASTM International, West Conshohocken, PA, USA.

[33] ASTM. 2008. C 230, Standard Specification for Flow Table for Use in Tests of Hydraulic Cement. ASTM International, West Conshohocken, PA.

[34] ASTM. 2014. C1679, Standard Practice for Measuring Hydration Kinetics of Hydraulic Cementitious Mixtures Using Isothermal Calorimetry. ASTM International, West Conshohocken, PA,

[35] ASTM. 2003. C618, Standard Specification for Fly Ash and Raw or Calcined Natural Pozzolan for Use as a Mineral Admixture in Portland Cement Concrete, ASTM International, West Conshohocken, PA. 